\title{
Assessing student dissatisfaction: No quality without accessibility
}

A formal evaluation study of our children's literature collection revealed that students' perceived dissatisfaction with the quality and extent of the collection was primarily due to problems with access.

The small-scale study consisted of three parts: Quality was determined by comparing a sample of titles against several review journals. Extent or breadth of the collection was measured by comparing our titles against several "best" lists. Access was evaluated by means of a user survey in questionnaire format, as well as a close examination of the classification system used for this collection and searching of problem titles in the online catalog. The survey also examined the users' perception of the quality and extent of our collection.

Whereas quality and extent adequately measured up to the standards we had established at the outset of the study, we found

ies Carlton C. Rochell will oversee management of the Society's library services to the public and develop joint programming for both institutions such as a centralized computer catalog system, book acquisitions and educational and public outreach programs. Among the enhancements planned to the Society's Library during the one-year agreement are: increasing library access from three days per week to five; loading the Society's database in to the NYU online system, establishing an affiliates program for scholars, mounting exhibits of the Society's collections at NYU, and having NYU oversee all current acquisitions, processing and cataloguing for the Historical Society; the resources of both institutions will be used for book preservation. This is not the first formal relationship between the two institutions; from 1841 to 1857 , the Society was in residence in NYU's original Main Building on Washington Square.

\section{Do the standards meet your needs?}

ACRL's University Libraries Section (ULS) is considering whether to revise the Standards for University Libraries, approved by the ACRL Board of Directors and the ALA Standards Committee in 1989. These standards are not prescriptive or quantitative, but focus on setting that problems with access were the major cause for students' dissatisfaction: e.g., proximity of the collection to the computer lab; inconsistent cataloging and classification practices; inadequate subject headings; the lack of cross-references (authority control) in the online catalog; but also students' inept use of the online catalog (typos, incorrect search strategies, unfamiliarity with limiting keyword searches, etc.).

A pathfinder to the collection with helpful hints how to search children's books in the online catalog; reclassification of some titles; addition of subject headings with the appropriate subdivision "juvenile literature" or "juvenile fiction"; and providing better physical access were among the immediate steps we took to making access to the collection a more satisfying experience for our students.-Susanne Nevin, Gustavus Adolphus College

goals and objectives and measuring the degree to which library performance meets these goals and objectives. As such, the standards may be durable even in the face of fairly dramatic changes occurring in university libraries. ULS would like your comments on the standards and is especially interested in hearing how individuals have used the standards. Comments on how developments since 1989 and those on the horizon might affect the stability of these standards are also requested. (Note: The Standards are printed in the September 1989 issue of CERL News, pages 679-691.) Send your comments to: ULS member-at-large Beverlee French by December 31, 1993, at Library Administration, Shields Library, University of California, Davis, CA 95616; e-mail: bafrench@ucdavis.edu; tel: (916) 752-2110; fax: (916) 752-6899.

\section{EBSS listserv address change}

The Education and Behavioral Sciences Section of ACRL has changed the location of its electronic discussion forum. EBSS-ALA is now available to EBSS members courtesy of the University of Maine. To subscribe, e-mail a request that includes your electronic address and full name to Deborah Rollins at rollins@maine.bitnet or rollins@maine.maine.edu. 